is reasonable having regard to the restricted range of their employment and the greater chance of external help in case of accident.

What remains to be demonstrated-and the task will not be an easy one-is whether the large number of lifeboats now thought to be essential can possibly be so carried as to be loaded and got into the water safely within a reasonable time after an accident has taken place-say within half an hour or an hour. Judging by the Titanic--in which case all the circumstances were most favourable to the loading and lowering of boats-radical changes will be required in the installation of lifeboats and in the means of lowering them, if this essential condition is to be fulfilled. All that need be added is that whatever may be the number of lifeboats carried, and however efficient may be the details of the arrangements for lowering these boats, it is obviously of primary importance to secure efficient watertight subdivision in passenger ships, so as to minimise the risk of foundering and to lengthen out the time which ships will remain afloat in cases of accidents so serious as to involve their final sinkage. On this matter another committee is still at work, and no action can be taken by the Board of Trade until its report has been presented.

\section{ATMOSPHERIC PRESSURE AND TEMPERATURE.}

IN Aus dem Archiv der deutschen Seewarte, I9II, No. 4, W. Brockmöller discusses the geographical distribution of the monthly range of oscillation of the barometer. So far as the southern hemisphere is concerned, the question was thoroughly investigated by $\mathrm{Dr}$. W. J. S. Lockyer in a recent publication of the Solar Physics Committee, but Herr Brockmöller's treatment of the subject covers a wider area, and is based on a different definition of the "range." He takes as the measure of this the mean value of the difference between the highest and lowest barometer readings for each month, and deals with a selection of stations, about 300 in all. After correcting the values for the periodic semi-diurnal variation, and for height above sea-level in the case of a few high-level stations, he plots the values for winter (DecemberFebruary), and for summer (June-August), and obtains two very interesting charts, showing the isobarometric lines, or lines of equal range. For the northern hemisphere he obtains also normals for different latitudes, and draws the isanomalies, or lines of equal departure from normal. The range is least, 3 or $4 \mathrm{~mm}$., in the equatorial region, and greatest near the arctic circle, apparently diminishing again towards the pole. The outstanding features are the maxima, in both seasons, near Iceland and the Aleutian Islands, the regions of the "permanent cyclones." The maxima are naturally much less intense in summer than in winter. Perhaps even more remarkable is the large value of the anomaly on the east coast of North America, where it is greater than at any other place. The effect is possibly due to the proximity of the division between the Labrador current and the warmer water of the North Atlantic, but it is deserving of further investigation.

In the same journal, No. 5, Prof. Köppen and Dr. Wendt discuss the vertical distribution of temperature over Hamburg between the earth's surface and a height of $3000 \mathrm{~m}$. The records obtained in nearly 1200 ascents of kites and balloons during the years 1904-9 have been analysed very thoroughly, and a new departure has been made in the special treatment of so-called inversions of temperature-gradient. The authors find that such inversions occur in 69 out of NO. 2238 , vol. go] every roo ascents, the temperature remaining constant or increasing with altitude. Inversions are most frequent in autumn and winter, and in December they are found in nearly every ascent. At all seasons they occur most frequently with southerly winds. Inversions in which the increase of temperature exceeds $3^{\circ} \mathrm{C}$. are almost invariably accompanied by a decrease in the relative humidity except for those which occur in the layer between the earth's surface and a height of $500 \mathrm{~m}$. At all seasons the sky is more frequently cloudy than clear on the occasions when inversions are recorded, but in spring and autumn the number of cases of clear sky is large. The clouds were found usually to have their lower surfaces below $500 \mathrm{~m}$., except in those cases in which inversions occurred below $500 \mathrm{~m}$. Another section of the paper deals with the dependence of temperature-gradient on wind direction. Near the surface the gradient is greatest with $\mathrm{N}$. winds, above $500 \mathrm{~m}$. with $\mathrm{W}$. winds, and above $1000 \mathrm{~m}$. with S.W. winds. As the wind usually veers with increasing height, it seems probable that the actual direction of the current for maximum gradient in the layer considered will be northerly at all heights.

\section{PLANKTON INVESTIGATIONS.}

IN the Bulletin Trimestriel, I9II, the second part of the "Résumé des Observations" continues the summary of the plankton investigations carried out under the international programme in the north-east Atlantic and north-west European waters during the years I902-8. The subjects here dealt with are the Copepoda, Tunicata, Ostracoda, Chætognatha, Amphipoda, Rotatoria, and Ceratium. With the vast amount of material collected in course of the investigations external records are incorporated in a discussion of the seasonal occurrence and distribution of the species considered, and the hydrographic conditions associated in each case with such. The annual and seasonal distribution and intensity of many of the more important species are shown in a number of separate charts. From an economic point of view, attention is directed to the importance of many of the Copepoda and Amphipoda as constituting in a large measure the food supply of Clupeoids, Gadidæ, the mackerel, and other marketable fishes.

As bearing directly on questions of physical oceanography, Salpa and Doliolum among the Tunicata afford important examples of warm-water species drifted as annual visitors to our coasts by the agency of the Gulf Stream. Similarly, several species of Ceratium show a distribution largely increased by immigration through the Faroe-Shetland Channel into the North and Norwegian Seas and beyond. Some of the latter species have a second sphere of distribution in the West Atlantic, from Florida to Newfoundland, and the author of this section, who has traced some of them sparingly at wide intervals across the Atlantic to the American coast, is of opinion that the two spheres of distribution are indeed in communication by virtue of the east-going oceanic movement. Conversely, among the brackish-water Rotatoria, species find their extension during the summer months from the Gulfs of Finland and Bothnia over the Baltic and outwards, mainly dependent on the periodic surface outflow of low-salinity water in this region. For the further elucidation of these complex problems, more exact information is required concerning some of the more critical species, and the need is felt, in particular, for a greater extension of the area of investigations to the westward and south-westward of Ireland. 